Abbreviated Key Title: Sch J Med Case Rep

ISSN 2347-9507 (Print) | ISSN 2347-6559 (Online)

Journal homepage: https://saspublishers.com/sjmcr/

\title{
Mac Master Syndrome: A Case Report
}

Souhil Errafia*, Imane El Bouchti

Rheumatology Department, Mohammed VI University Hospital, PO Box 2360 Principal, Avenue Ibn Sina, Postal code 40000, Marrakesh, Morocco

DOI: $10.36347 /$ simcr.2020.v08i09.013

| Received: 13.09.2020 | Accepted: 20.09.2020 | Published: 24.09.2020

*Corresponding author: Souhil Errafia

Abstract

Case Report

Mac Master syndrome or osteochondrosis of the ischial tuberosity is a rare disease in children and young adults, characterized by apophyseolysis of the ischial tuberosity. We report a case of a 54-year-old woman having a chronic buttock pain. The computed tomography scan showed an ossification of the right ischial tuberosity, caused by a neglected fracture.

Keywords: Buttock pain, ischial tuberosity, apophysitis, osteochondrosis, Mac Master.

Copyright @ 2020: This is an open-access article distributed under the terms of the Creative Commons Attribution license which permits unrestricted use, distribution, and reproduction in any medium for non-commercial use (NonCommercial, or CC-BY-NC) provided the original author and source are credited.

\section{INTRODUCTION}

Osteochondrosis is a rare disease, which occurs in children and young adults following repeated and often unnoticed trauma [1].

\section{OBSERVATION}

We report the case of a 54-year-old female patient with no history of trauma, who consulted for intermittent pain in the buttocks since early childhood.
Clinical examination revealed a painful lump over the right ischium. Pelvic computed tomography revealed a heterogeneous ischial ossification (an ischium osteochondrosis sequelae). The treatment was based on rest, adoption of a healthy lifestyle (sport restriction for 2 months then gradual resumption, wearing orthotic insoles and avoiding squats) also a medical treatment (anti-inflammatory and analgesic drugs). A satisfactory improvement was noticed.

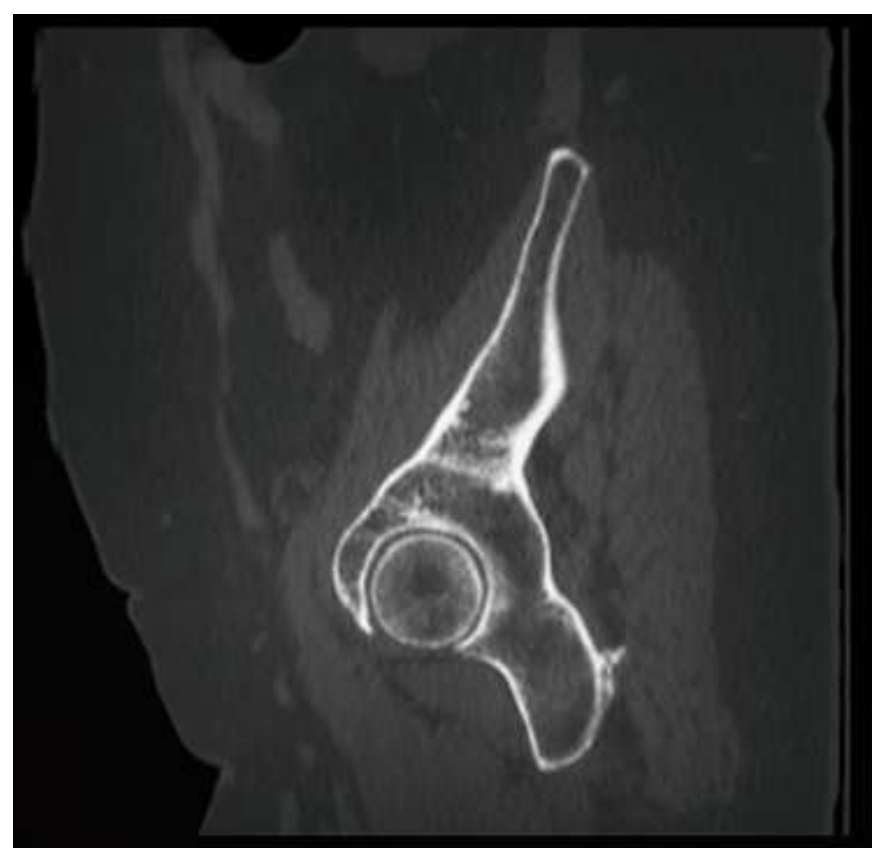

Fig-1: Sagittal section from the computed tomography of the pelvis showing a calcification next to the right ischial tuberosity (a result of osteochondrosis) 


\section{DISCUSSION}

Mac Master syndrome or the ischial tuberosity osteochondrosis is a disease of children and young people characterized by an apophysiolysis of the ischial tuberosity [1]. This alteration of the bone process can lead to an apophysitis [2]. The usual mechanism is a repeated traction on the growing cartilage $[2,3]$. The final stage is a complete bone removal resulting in hypertrophic ossification of the ischium [3]. Radiographically, there are initially irregularities on the outer edge of the ischiopubic branch, surrounded by a small fragmented linear opacity, that is well objectified by computed tomography. In severe forms, a fracture may be observed. Later, the ischium appears stocky and massive, or sometimes pseudo-spherical indicating a state of sequelae [3]. Symptomatic treatment is the rule in non-fracture cases: rest, temporary sport stoppage, avoiding the hamstring exercises (for example: tackles during football), wearing orthotic insoles, antiinflammatory drugs prescription and early rehabilitation. Surgery should be considered in the case of an unconsolidated fracture (fix bone using screws) or if the medical treatment has failed (removal of an ossification) [1-3].

\section{CONCLUSION}

Mac Master osteochondrosis is a benign disease mainly affecting athletic adolescents. Its discovery in adults in the absence of functional signs in childhood is rare. Its appearance can be extremely misleading and could be a differential diagnosis for bone tumors.

Declaration of interests: The authors declare that they have no conflict of interest.

\section{REFERENCES}

1. Thépaut M. Apophysoses de croissance. La Lettre du Rhumatologue. 2013; 394. Available from: https://www.edimark.fr/lettre-

rhumatologue/apophysoses-croissance (access on 30/06/2020).

2. Sailly M. Apophysites - Revue de la littérature et nouvelles directions. Schweizerische Zeitschrift fur Sportmedizin und Sporttraumatologie. 2014; 62(3):14-19.

3. Berger J. Le syndrome de Mac: A propos d'un nouveau cas d'arrachement tubérositaire de l'ischion. Orthop Traumatol. 1994;4:253-55. 